\title{
Evaluation of the efficacy of intra-articular tranexamic acid in patients with hypertension undergoing simultaneous bilateral total knee arthroplasty
}

\section{Eşzamanlı bilateral total diz artroplastisi uygulanan hipertansiyonlu hastalarda intra-artiküler tranexamik asit etkinliğinin değerlendirilmesi}

\author{
Adem Cobden ${ }^{1}$, Yalkin Camurcu ${ }^{2}$, Hanifi Ucpunar ${ }^{2}$, Huseyin Demirel ${ }^{1}$ \\ Halill Gök $k^{1}$, Mehmet Kis ${ }^{1}$
}

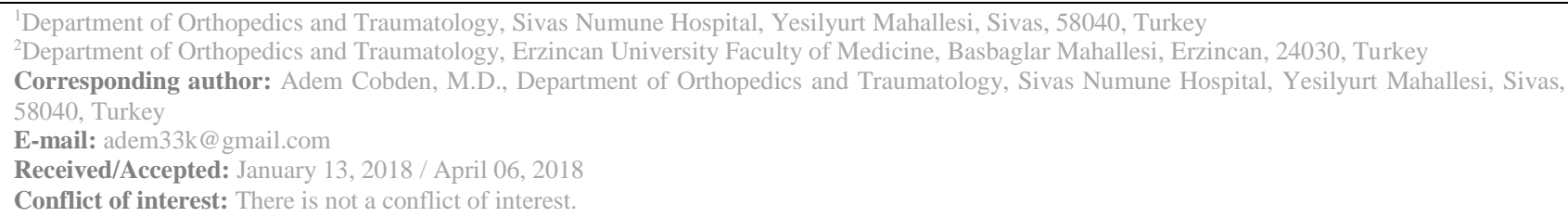

\section{SUMMARY}

Objective: The relationship between hypertension (HT) and increased perioperative transfusion rate in patients who underwent total knee arthroplasty (TKA) was previously investigated in the literature. This phenomenon may also increase the need for blood transfusion in patients who underwent bilateral simultaneous TKA despite using tranexamic acid (TXA). The main purpose of this study was to evaluate the decrease in hemoglobin levels and need for blood transfusion in patients with the diagnosis of HT who underwent bilateral simultaneous TKA after intra-articular (IA) administration of TXA in comparison to those who did not receive TXA.

Method: One hundred and ninety-one patients with the diagnosis of HT who underwent bilateral simultaneous TKA and fulfilled the criteria, were evaluated in this retrospective study. Patients were grouped as TXA group (individuals who received IA TXA) and control group (did not receive TXA). Primary outcome measures were decrease in hemoglobin levels and number of blood units transfused.

Results: Both groups were similar in age, gender, body mass index and American Society of Anesthesiologist (ASA) score and no statistically significant differences were observed. There was also no statistically significant difference between groups in terms of decrease in hemoglobin levels $(\mathrm{P}=0.844)$ and number of blood units transfused $(\mathrm{P}=0.095)$.

Conclusions: According to our results, in patients with the diagnosis of HT undergoing simultaneous bilateral TKA procedure, no significant difference was observed in the decrease of hemoglobin level and number of blood units transfused between patients who received IA TXA in comparison to those who did not receive TXA.

Keywords: Tranexamic acid; hypertension; total knee arthroplasty; blood loss; blood transfusion; hemoglobin level. 
Yöntem: Bu retrospektif çalışmada, eşzamanlı bilateral TDA uygulanan ve kriterlere uyan HT tanılı 191 hasta değerlendirildi. Hastalar TXA grubu (IA TXA alanlar) ve kontrol grubu (TXA almayanlar) olarak gruplandırıldı. Temel sonuç olarak belirleyiciler, hemoglobin düzeyleri ve kan transfüzyonu ünite sayısında azalma idi.

Bulgular: Her iki grup yaş, cinsiyet, vücut kitle indeksi ve Amerikan Anesteziyoloji Derneği (ASA) skoru bakımından benzerdi ve istatistiksel olarak anlamlı bir farkl111k gözlenmedi. Hemoglobin düzeylerinde $(\mathrm{P}=0.844)$ azalma ve kan transfüzyonu ünite sayısı $(\mathrm{P}=0.095)$ açısından gruplar arasında istatistiksel olarak anlamlı fark yoktu.

Sonuç: Bulgularımıza göre, eşzamanlı bilateral TKA prosedürü uygulanan HT tanılı hastalarda, IA TXA alan ve almayan hastalar arasında hemoglobin seviyesinin azalması ve kan transfüzyonu ünite sayısı arasında istatistiksel olarak anlamlı fark bulunamamıştır.

Anahtar sözcükler: Traneksamik asit; hipertansiyon; total diz artroplastisi; kan kaybı; kan nakli; hemoglobin seviyesi.

\section{INTRODUCTION}

Total knee arthroplasty (TKA) is one of the most common operations performed in orthopedic surgery, which is associated with potential risk of blood transfusion resulting from perioperative blood loss. According to reported studies in the literature, the rate of blood transfusion is more significant in patients undergoing simultaneous bilateral TKA ${ }^{1,2}$. Perioperative bleeding represents a particular concern in the setting of bilateral TKA, with reported increased allogenic blood transfusion rates $^{3,4}$. Allogenic blood transfusion carries the risk of disease transmission, hemolytic anemia, anaphylaxis, and graft-versus-host disease, as well as increased overall healthcare costs ${ }^{5}$. In the other hand, previous studies have reported that hemodynamic changes related to bilateral TKA could result in hematoma, increased risk of infection, delayed rehabilitation, and prolonged length of hospital stay and complications such as deep vein thrombosis, pulmonary embolism ${ }^{6,7}$.

Tranexamic acid (TXA) is proved as a safe and cost-effective anti-fibrinolytic agent that inhibits activation of plasminogen to plasmin leading to a decrease in fibrinolytic activity and stabilizing clotting $^{8,9}$. Tranexamic acid has gained significant popularity in total joint replacements given its potential benefits in terms of decreasing intraoperative blood loss and need for blood transfusion ${ }^{10,11}$. The intra-articular (IA) application of TXA into the knee joint could potentially have the same beneficial effects as intra venous administration ${ }^{12,13}$.
We noted some studies in the literature reporting relationship between systemic hypertension and increased perioperative transfusion rate in patients who underwent TKA ${ }^{14,15,16}$. However, in his recent study, Russo et al did not find a significant relationship between transfusion rates and hypertension during TKA procedure ${ }^{17}$. We hypothesized that the need for blood transfusion may increase in patients with the diagnosis of hypertension (HT) who underwent simultaneous bilateral TKA despite using TXA. Therefore, the main purpose of this study was to evaluate the decrease in hemoglobin levels and need for blood transfusion in patients with the diagnosis of HT who underwent bilateral simultaneous TKA after intra-articular (IA) administration of TXA in comparison to those who did not receive TXA.

\section{MATERIAL AND METHODS}

\section{Study Population}

The data of 243 patients with a previous diagnosis of HT who underwent elective bilateral simultaneous TKA between 2013 and 2016 were included in this retrospective study. Patients who were lost to follow-up, with thromboembolic and coagulation disorders, with cardiovascular and cerebrovascular diseases, and using anti-coagulant agent preoperatively were excluded from the study. A total of 191 patients with the diagnosis of HT who underwent bilateral simultaneous TKA were evaluated in the study (Fig.1). 


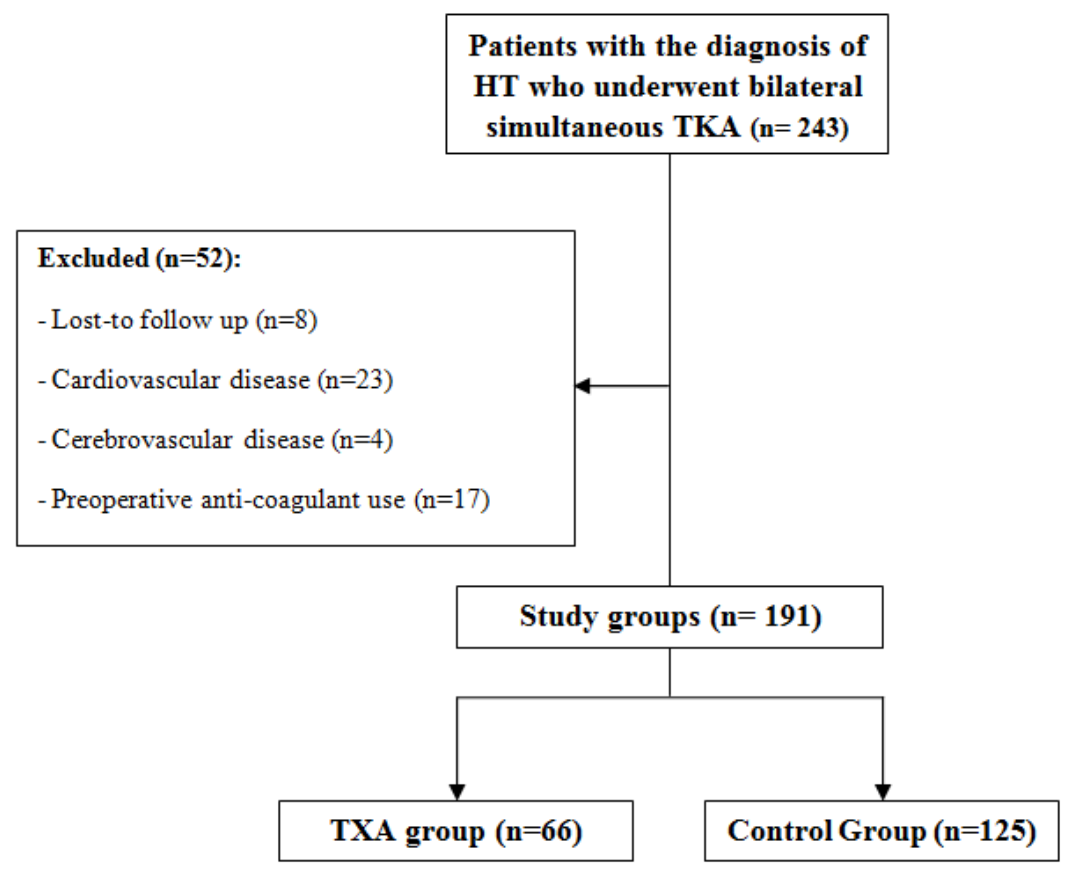

Fig.1 Flowchart diagram of the study. n:number of patients, HT: hypertension, TKA: total knee arthroplasty, TXA: tranexamic acid.

\section{Surgical Technique}

All bilateral simultaneous TKA procedures were performed by three senior surgeons under regional or general anesthesia. All patients received 2 grams of cephalosporin 30 minutes prior to operation. Pneumatic tourniquet was applied around the upper part of the thigh bilaterally, which was inflated to a pressure of $350 \mathrm{~mm} \mathrm{Hg}$. All bilateral TKA procedures were performed through standard medial parapatellar approach by using a surgical technique standardized to the same design of cemented knee prosthesis (Vanguard ${ }^{\circledR}$ Knee System, Zimmer Biomet Inc, IN, USA). Patients were grouped according to the administration of IA TXA during surgery. One senior surgeon routinely administrated IA TXA during bilateral simultaneous TKA procedure; where as other two surgeons did not administrate TXA. Sixty-six of 191 patients $(34.6 \%)$ received IA TXA (TXA group) and remaining 125 patients (65.4\%) did not receive TXA (control group). In the TXA group, 1 gram of IA TXA (Transamine ${ }^{\circledR}$, Actavis, Istanbul, Turkey) diluted in $100 \mathrm{~mL}$ of saline was applied to the joint surface before closure of the wound for each knee. Wound closure was performed after hemostasis was achieved with electrocautery. A suction drain was placed in both knees and clamped for 2 hours. Postoperative intravenous antibiotics were continued for 72 hours. The same postoperative treatment protocol was used for all patients. All drains were removed at first postoperative day and patients were mobilized with the support of walker. Allogenic blood transfusion was indicated in patients with hemoglobin levels less than $8 \mathrm{mg} / \mathrm{dL}$ or for those with hypovolemic signs. All patients received low-molecular-weight heparin for thromboembolic prophylaxis until the end of postoperative $4^{\text {th }}$ week.

\section{Outcome Measurements}

Patients' demographics such as age, gender, and body mass index (BMI) were recorded. American Society of Anesthesiologists (ASA) score, anesthesia technique (regional/general), operative time (minutes), and total length of hospital stay (days) were also recorded for all patients. Primary outcome measures were decrease in hemoglobin levels and number of blood units transfused for all patients. Intraoperative blood loss was negligible in all patients because of use of a tourniquet. Preoperative hemoglobin level measurement was performed for all patients one day prior to surgery. Postoperative hemoglobin level measurement was performed prior to discharge and the patient was considered as hemodynamically stable. The decrease in hemoglobin levels was then calculated. Postoperative major medical and orthopedic complications during follow-ups were also noted. 


\section{Statistical analysis}

Statistical analysis was performed by SPSS 20.0 (SPSS Inc, IL, USA). Numerical variables were given as mean \pm standard deviation, and categorical variables were given as frequency and (percent). The comparison of mean values between two groups was performed by t-test or Mann Whitney $\mathrm{U}$ test in accordance to Shapiro Wilk normality test. The comparison of frequencies was performed by Chi-Square test. $P$ values lower than 0.05 was considered as statistically significant. Post hoc power analysis was performed by $G$ Power software.

\section{RESULTS}

The mean follow-up time of the patients was 23 months. The baseline demographics and clinical characteristics were demonstrated in Table 1 . There was no significant difference between groups in terms of patients' age, gender, BMI and ASA scores. The mean preoperative and postoperative hemoglobin levels as well as decrease in hemoglobin levels were not significantly different when two groups were compared. In addition to that, no significant difference was observed between groups in the mean number of blood untis transfused. The comparison of groups in total operation time and length of hospital stay revealed no significant difference (Table 1).

Table 1. Baseline demographics and clinical characteristics of the patients.

\begin{tabular}{lccc}
\hline & $\begin{array}{c}\text { TXA group } \\
(\mathbf{n = 6 6 )}\end{array}$ & $\begin{array}{c}\text { Control group } \\
(\mathbf{n = 1 2 5})\end{array}$ & p values \\
\hline Demographics & & & \\
$\quad$ Gender & $62(94 \%)$ & $116(93 \%)$ & $0.819^{*}$ \\
$\quad$ Female & $4(6 \%)$ & $9(7 \%)$ & \\
$\quad$ Male & $68.6 \pm 7.3$ & $69.4 \pm 6.9$ & $0.564^{* *}$ \\
Age (years) & $27.5 \pm 4.2$ & $27.6 \pm 4.1$ & $0.899^{* *}$ \\
BMI (kg/m $\left.{ }^{2}\right)$ & & & $0.319^{*}$ \\
ASA score & $0(0 \%)$ & $0(0 \%)$ & \\
ASA I & $48(73 \%)$ & $83(66 \%)$ & \\
ASA II & $16(24 \%)$ & $35(28 \%)$ & \\
ASA III & $2(3 \%)$ & $7(6 \%)$ & \\
ASA IV & & & \\
Hemoglobin Levels $(\boldsymbol{m g} / \boldsymbol{d L})$ & $13.6 \pm 1.1$ & $13.6 \pm 1.0$ & $0.802^{* *}$ \\
Preoperative & $10.2 \pm 1.1$ & $10.2 \pm 0.9$ & $0.978^{* *}$ \\
Postoperative & $3.3 \pm 1.6$ & $3.3 \pm 1.0$ & $0.844^{* *}$ \\
Decrease in hemoglobin level &
\end{tabular}

\section{Operative Data}

Anesthesia Technique

$0.609 *$

$$
\begin{aligned}
& \text { Regional } \\
& \text { General }
\end{aligned}
$$

$$
\begin{array}{cc}
62(94 \%) & 120(96 \%) \\
4(6 \%) & 5(4 \%)
\end{array}
$$

Total Operation Time (minutes)

$139.8 \pm 27.6$

$138.2 \pm 23.2$

$0.785 * *$

\section{Postoperative Data}

\begin{tabular}{llll} 
Number of blood transfused (unit) & $3.2 \pm 0.7$ & $3.5 \pm 1.1$ & $0.095 * *$ \\
Length of Hospital Stay (days) & $8.3 \pm 5.0$ & $8.1 \pm 3.1$ & $0.589 * *$ \\
\hline * p value according to Chi-Square test \\
** p value according to t-test \\
TXA: tranexamic acid, BMI: bosy mass index, ASA: American Society of Anesthesiologists
\end{tabular}


Two major orthopedic complications and two major medical complications were observed in the TXA group during follow-up. Six major orthopedic complications and two major medical complications were observed in the control group. The list of major complications was demonstrated in Table 2.

Table 2. Postoperative major complications observed during follow-up.

\begin{tabular}{lcc}
\hline & $\begin{array}{c}\text { TXA group } \\
(\mathbf{n}=\mathbf{6 6})\end{array}$ & $\begin{array}{c}\text { Control group } \\
(\mathbf{n = 1 2 5})\end{array}$ \\
\hline Major Orthopedic Complications & & \\
$\quad$ Deep wound infection & 1 & 4 \\
Patella luxation & 1 & 1 \\
Aseptic loosening & 0 & 1 \\
$\quad$ Total & $2(6.4 \%)$ & $6(4.8 \%)$ \\
\hline Major Medical Complications & & \\
$\quad$ Pulmonary embolus & 1 & 0 \\
Cerebrovascular accident & 0 & 1 \\
$\quad$ Myocardial infarction & 1 & 1 \\
Total & $2(6.4 \%)$ & $2(1.6 \%)$ \\
\hline
\end{tabular}

TXA: tranexamic acid

\section{DISCUSSION}

The most important finding of the present study was that we did not observe a significant difference in hemoglobin levels and transfusion needs between TXA and control groups in patients with the diagnosis of HT undergoing simultaneous bilateral TKA procedure. Chen et al reported a significant decrease in hemoglobin level, transfusion rate, and transfused blood units in patients who received fixed dose intra-veneous (IV) TXA during bilateral simultaneous TKA procedure compared to the control group who received saline ${ }^{18}$. Zhu et al reported a $22.2 \%$ decrease in blood transfusion rate compared to control group after IA TXA wash ${ }^{19}$. Except from the reported studies in the literature, IA TXA wash was not superior to control group in terms of decreasing hemoglobin levels and number of blood units transfused according to our results.

We administrated IA TXA during bilateral simultaneous TKA that also has been proved as efficient as IV administration in decreasing blood loss according to the studies reported in the literature. Aggarwal et al reported that IA TXA wash during bilateral TKA procedure was better than IV TXA administration in blood loss and clinical outcome ${ }^{20}$. However, Patel et al and Hegde et al found no significant difference in blood loss and transfusion rate between IA and IV TXA administration in patients who underwent bilateral simultaneous TKA [12,21]. The similar results obtained from this study in terms of hemoglobin levels and number of blood units transfused may also be interpreted as the decreased efficacy of TXA wash during bilateral simultaneous TKA.

In the literature, previous studies reported that advanced age, high blood pressure, increased timing of tourniquet release, preoperative low hemoglobin levels, and preoperative use of anticoagulation drugs negatively influences perioperative allogenic blood transfusion rates ${ }^{22-24}$. According to our current knowledge, hypertension is a predisposing factor for vascular thrombosis and coagulation in patients with vascular integrity. However, when vessel wall injury has occurred, aggregation, adhesion of platelets, and other pathways of the coagulation cascade may not process adequately due to the mechanical effect of high blood pressure. In addition, intraoperative and postoperative blood pressure changes may contribute to increased perioperative bleeding. In our study, we evaluated a relatively homogeneous patient population with no significant difference in demographics, ASA scores, or preoperative hemoglobin levels. Besides, all bilateral simultaneous TKA procedures were performed with the same treatment protocol, with similar 
anesthesia technique, operative time, as well as tourniquet time. Thus, clinical parameters, which influenced increased blood loss (such as advanced age, gender, suction drainage, preoperative low hemoglobin levels, anesthesia technique, operative time, and perioperative anti-coagulant protocol), cannot be taken into consideration. From this point of view, we could easily evaluate the effect of TXA in patients with the diagnosis of systemic hypertension in comparison to those who did not receive TXA. Our results may be explained as such: Impaired hemodynamic response due to systemic HT may contribute to increased blood loss although TXA was administrated. In their retrospective study, Pola et al also emphasized that hypertension is one of the risk factors significantly associated with perioperative blood loss in nonanemic patients who underwent total hip arthroplasty ${ }^{25}$. This issue should be investigated by further prospective randomized studies to achieve a higher level of evidence.

During follow-up period, we encountered one pulmonary embolus (PE) case in the TXA group, and none was encountered in the control group. A meta-analysis reported a combined incidence of deep venous thrombosis (DVT) of 5\% in the TXA group and $5.5 \%$ in controls, leading to the conclusion that there was no increase in risk of thromboembolism with TXA administration in patients without a history of thromboembolic disease $^{26}$. Authors did not report the incidence of $\mathrm{PE}$ in their study ${ }^{26}$. Barrett et al reported PE in $1.44 \%$ of patients who underwent simultaneous bilateral TKA procedure ${ }^{27}$. In a study evaluating DVT and PE after TKA by radionuclide venography, authors found DVT in $24 \%$ of asymptomatic patients and PE in $12 \%$ of asymptomatic patients ${ }^{28}$. Thus, the actual incidence of asymptomatic DVT and PE may be much higher. Myocardial infarction was observed in both groups, and cerebrovascular accident (stroke) was observed in the control group. In their metaanalysis, Restrepo et al also reported higher risk of cardiac complications, PE, and mortality after simultaneous bilateral TKA ${ }^{29}$.

We noted some limitations for this study. Firstly, we had lack of data about blood pressure monitoring during surgery and postoperative hospitalization. However, all patients were prevented from intraoperative and postoperative changes of blood pressure by anesthesiologists and physicians during surgery and postoperative care. Secondly, we had no data about postoperative drain output. By this reason, we aimed to measure the overall hemoglobin decrease of patients compared to preoperative hemoglobin levels by evaluating the postoperative hemoglobin level prior to discharge when patients were considered as hemodynamically stable. The main strength of this study was, being the first study in the literature evaluating the efficacy of IA TXA wash in transfusion needs of patients with the diagnosis of HT undergoing simultaneous bilateral TKA. In addition to that, we have evaluated a relatively homogeneous and large patient population treated with the same treatment protocol in a single center with no significant difference in baseline demographics and clinical characteristics. We did not apply a priori calculation for the sample size, however, post hoc analysis was performed for each of the variables and the lowest statistical power was 0.88 with an alpha value of 0.05 .

\section{CONCLUSION}

According to our results, in patients with the diagnosis of HT undergoing simultaneous bilateral TKA procedure, no significant difference was observed in the decrease of hemoglobin level and number of blood units transfused between patients who received IA TXA in comparison to those who did not receive TXA.

\section{REFERENCES}

1. Parvizi J, Chaudhry S, Rasouli MR, et al. Who needs autologous blood donation in joint replacement? J Knee Surg 2011;24(01):25-31

2. Bierbaum BE, Callaghan JJ, Galante JO, Rubash HE, Tooms RE, Welch RB. An analysis of blood management in patients having a total hip or knee arthroplasty. J Bone Joint Surg Am 1999;81(01):2-10

3. Bullock DP, Sporer SM, Shirreffs TG Jr. Comparison of simultaneous bilateral with unilateral total knee arthroplasty in terms of perioperative complications. J Bone Joint Surg A 2003;85-A;(10):1981-1986

4. Jankiewicz JJ, Sculco TP, Ranawat CS, Behr C, Tarrentino S. One stage versus 2-stage bilateral total knee arthroplasty. Clin Orthop Relat Res 1994;(309):94-101

5. Ponnusamy KE, Kim TJ, Khanuja HS. Perioperative blood transfusions in orthopaedic surgery. J Bone Joint Surg Am 2014;96(21): 1836

6. Levine BR, Haughom B, Strong B, Hellman M, Frank RM. Blood management strategies for total knee arthroplasty. J Am Acad Orthop Surg. 2014;22:361-71.

7. Wang J, Wang Q, Zhang X, Wang Q. Intraarticular Application is More Effective Than 
Intravenous Application of Tranexamic Acid in Total Knee Arthroplasty: A Prospective Randomized Controlled Trial. J Arthroplasty. 2017;32(11):3385-3389

8. Yang Z G, Chen W P, Wu L D. Effectiveness and safety of 323 tranexamic acid in 324 reducing blood loss in total knee arthroplasty: a meta-analysis. J Bone Joint Surg Am 2012;94(13): 1153-1159.

9. Springer BD, Odum SM, Fehring TK. What Is the Benefit of Tranexamic Acid vs Reinfusion Drains in Total Joint Arthroplasty? J Arthroplasty 2016;31(1):76-80.

10. Prieto HA, Vincent HK, Deen JT, Iams DA, Parvataneni HK. Tranexamic Acid Effectively Reduces Blood Loss and Transfusion Rates during Simultaneous Bilateral Total Knee Arthroplasty. J Knee Surg. 2017 May 15. doi:10.1055/s-0037-1603333. [Epub ahead of print]

11. Dunn CJ, Goa KL. Tranexamic acid: a review of its use in surgery and other indications. Drugs 1999;57(06):1005-1032

12. Patel JN, Spanyer JM, Smith LS, Huang J, Yakkanti MR, Malkani AL. Comparison of intravenous versus topical tranexamic acid in total knee arthroplasty: a prospective randomized study. J Arthroplasty 2014; 29(8): 1528-31.

13. Chimento GF, Huff T, Ochsner JL,Jr, Meyer M, Brandner L, Babin S. An evaluation of the use of topical tranexamic acid in total knee arthroplasty. J Arthroplasty 2013; 28: 74-7.

14. Durasek J, Dovzak-Bajs I, Sarić V. [Factors affecting blood loss in total knee arthroplasty patients]. Acta Med Croatica 2010;64(3):20914. Croatian.

15. Kulej M, Dragan S, Płocieniak K, Krawczyk A, Dragan SŁ, Baryła-Urban P. Evaluation of blood loss and significance of postoperative autotransfusion in knee joint alloplasty. Ortop Traumatol Rehabil 2012;14(1):31-40. English, Polish.

16. Borghi B, Oriani G, Bassi A. Blood saving program: a multicenter Italian experience. Int $\mathbf{J}$ Artif Organs 1995;18(3):150-8.

17. Russo RR, Dasa V, Duarte R, Beakley B, Mishra M, Thompson H. Post-operative hypertension after total knee arthroplasty and the effects on transfusion rates. PLoS One 2012;7(12):e50967.

18. Chen X, Cao X, Yang C, Guo K, Zhu Q, Zhu J. Effectiveness and Safety of Fixed-Dose Tranexamic Acid in Simultaneous Bilateral Total Knee Arthroplasty: A Randomized Double-Blind Controlled Trial. J Arthroplasty 2016;31(11):2471-2475.
19. Zhu M, Chen JY, Yew AK, Chia SL, Lo NN, Yeo SJ. Intra-articular tranexamic acid wash during bilateral total knee arthroplasty. J Orthop Surg (Hong Kong) 2015;23(3):290-3.

20. Aggarwal AK, Singh N, Sudesh P. Topical vs Intravenous Tranexamic Acid in Reducing Blood Loss After Bilateral Total Knee Arthroplasty: A Prospective Study. J Arthroplasty 2016;31(7):1442-8.

21. Hegde C, Wasnik S, Kulkarni S, Pradhan S, Shetty V. Simultaneous bilateral computer assisted total knee arthroplasty: the effect of intravenous or intraarticular tranexamic acid. J Arthroplasty 2013;28(10):1888-91.

22. Bell TH, Berta D, Ralley F, Macdonald SJ, McCalden RW, Bourne RB, Rorabeck $\mathrm{CH}$, Naudie DD. Factors affecting perioperative blood loss and transfusion rates in primary total joint arthroplasty: a prospective analysis of 1642 patients. Can J Surg 2009;52(4):295-301

23. Bong MR, Patel V, Chang E, Issack PS, Hebert R, Di Cesare PE. Risks associated with blood transfusion after total knee arthroplasty. J Arthroplasty 2004;19(3):281-7.

24. MacGillivray RG, Tarabichi SB, Hawari MF, Raoof NT. Tranexamic acid to reduce blood loss after bilateral total knee arthroplasty: a prospective, randomized double blind study. $\mathrm{J}$ Arthroplasty 2011;26(1):24-8.

25. Pola E, Papaleo P, Santoliquido A, Gasparini G, Aulisa L, De Santis E. Clinical factors associated with an increased risk of perioperative blood transfusion in nonanemic patients undergoing total hip arthroplasty. J Bone Joint Surg Am 2004;86-A(1):57-61.

26. Ho KM, Ismail $H$. Use of intravenous tranexamic acid to reduce allogenic blood transfusion in total hip and knee arthroplasty: a meta-analysis. Anaesth Intensive Care 2003;31:529.

27. Barrett J, Baron JA, Losina E, et al. Bilateral total knee replacement: staging and pulmonary embolism. J Bone Joint Surg (Am) 2006;88:2146.

28. Pookaranjanamorakot C, Sirisriro R, Eurvilaichit $\mathrm{C}$, et al.The incidence of deep vein thrombosis and pulmonary embolism after total knee arthroplasty: the screening study by radionuclide venography. J Med Assoc Thai 2004;87:869.

29. Restrepo C, Parvizi J, Dietrich T, Einhorn TA. Safety of simultaneous bilateral total knee arthroplasty. A meta-analysis. J Bone Joint Surg Am 2007;89(06):12201226. 